\title{
Association Between Awareness of Basic Public Health Services And Vaccination Rates Among Migrants In China: A Nationwide Cross-Sectional Study
}

\author{
Jun Wang \\ Renmin University of China \\ Jingmin Zhu \\ University of Birmingham \\ Yang Bai ( $\sim$ baiyangbeatrice@163.com ) \\ Renmin University of China \\ Xueyao Wang \\ Renmin University of China \\ Yue Che \\ Renmin University of China \\ Jue Liu \\ Peking University Health Science Centre
}

\section{Research Article}

Keywords: basic public health services, recommended vaccines, migrants, China

Posted Date: September 8th, 2021

DOI: https://doi.org/10.21203/rs.3.rs-860427/v1

License: (c) (i) This work is licensed under a Creative Commons Attribution 4.0 International License. Read Full License 


\section{Abstract}

Cross-sectional studies about association between awareness of basic public health services and vaccination rates among migrants were lacking. In this study, we aimed to explore the association between awareness of the BPHSs project and vaccination rates among the migrants in China. We included 10013 respondents aged 15 years old or above of eight provinces from 2017 Migrant Population Dynamic Monitoring Survey in China, a nationwide cross-sectional study. Multivariable logistic regressions were used to assess the association between awareness of basic public health services and vaccination rates. Among 10013 migrants, $76.48 \%$ were aware of the BPHSs project. Female, the middle-aged, married or having a relationship, the highly educated and the healthy population had higher awareness of this project than others. Multivariable logistic regressions showed that there were significant associations between the awareness of BPHSs project and vaccination rates of eight recommended vaccines (all $p$ values $<0.001$ ), including HepA vaccine (OR: 1.54, 95\%Cl: 1.38-1.73), FIn vaccine (OR: 1.28, 95\%Cl: 1.13-1.44), JE vaccine (OR: 1.33, 95\% Cl: 1.14-1.54), TIG vaccine (OR: 1.28, 95\%Cl: 1.11-1.48), HepB vaccine (OR: 1.11, 95\%Cl: 1.01-1.22), DTaP vaccine (OR: 1.22, 95\%Cl: 1.05-1.43), MPSV vaccine (OR: 1.28, 95\%Cl: 1.08-1.51), HF vaccine (OR: 1.32, 95\% Cl: 1.03-1.70), except for JE vaccine. The results were robust in the sensitivity analysis. There was a strong relationship between the awareness rate of BPHSs project in the migrants and vaccination. Our findings indicated that the promotion of basic public health services had a beneficial effect on the national recommended vaccination coverage, especially for the migrants with relatively low vaccine coverage.

\section{Introduction}

In order to promote health status, Chinese government had introduced tons of policies, and the National Basic Public Health Services (BPHSs) project was one of these [1, 2]. It had been more than ten years since China began to implement this project, which was set to provide equitable basic healthcare services for residents in any area. As one of the key-reform policies of the "new medical reform" in 2009, and based on the practical challenges at that time, this project covered maternal and child health care, elderly health care, chronic disease management, vaccination, health education, and gradually became the main source of income for primary care institutions [3]. The service quality and financial support of BPHSs project had continuously improved during the past years, and this project had promoted the equalization of basic health services in China.

In this project, vaccination was one of the most significant items, which was found to be the most effective and efficient way for preventing illness and keeping fit [4. 5]. This program asked people be vaccinated with HepB vaccine, BCG vaccine, polio vaccine, DPT vaccine, measles vaccine, HepA vaccine, meningitis vaccine, encephalitis vaccine, measles vaccine and other national immunization program vaccines. What was more, in key areas, the government also provided targeted vaccination for key populations, including hemorrhagic fever with renal syndrome vaccine, anthrax vaccine, and leptospirosis vaccine [5].

There was not much literature on BPHSs project in previous studies. The exiting studies had focused on the equalization, financing, and performance appraisal of BPHSs projects [6-12]. In terms of service content, previous studies focused on the management of diabetes and hypertension, the improvement of health literacy, and the establishment of health files, while less attention was paid to vaccination [13-17]. In these research, BPHSs project was proved to relate to effective control of chronic diseases [14-17], the establishment of health records [13] and so on.

As to the awareness of BPHSs project, scholars did many research based on national or local conditions [18-22]. For example, Xu et al. conducted a survey of 733 residents in Anhui Province, and the results showed that the awareness rate of the BPHSs project was $21.86 \%$ [22]. Wang et al. conducted a survey on key population of this project in Gansu Province, and found that the awareness rate of this population was $66.85 \%$, of which the awareness rate of vaccination was as high as $98.53 \%$ [19]. Hao et al. found that the overall awareness rate of Guangdong residents about the free service policy of national basic public health service items was 13.52\% (284/2100) [18]. Guo et al. selected Beijing, Shanghai, and Shenzhen as the research sites, in each city 2 districts were randomly selected, 5 streets in each district, 100 migrants in each street were selected as the research objects, and 2504 people were effectively investigated. The study found that the awareness rate of basic public health services of the migrants was low, at $37.5 \%$. Among all the projects, the awareness rate of vaccination was the highest, as high as $34.4 \%$ [21].

However, compared with other aspects, present research paid less attention to vaccination and the association between vaccination rates and the awareness of BPHSs project. Meanwhile, although there were studies focused on the awareness of BPHSs project among migrants, they only did research on the developed areas (such as Beijing, Shanghai, Guangzhou, etc.) and lacked the analysis of the overall situation of the migrants across the country. In this study, we aimed at studying the vaccination status of the migrants nationwide and the awareness of the BPHSs project. The most important thing was that we would analyze the relationship between the awareness of BPHSs project and vaccination rates through this research, to propose relevant policy recommendations for increasing the vaccination rates of the migrants based on the BPHSs project.

\section{Materials And Methods}

\subsection{Data collection and study design}

In this study, we used data from 2017 Migrant Population Dynamic Monitoring Survey (MDMS), which was a nationally representative demographic and health survey of migrant population conducted by National Health and Family Planning Commission of the People's Republic of China(NHFPC). The sample of this survey were Chinese internal migrants who were or older than 15 years old when the study conducted and it required that the interviewee must live in a place other than the place of residence for more than one month. 
According to the needs of the management of the health and family planning services of the migrants and policy research, based on the principle of randomness, sample sites were drawn from the 31 provinces (autonomous regions, municipalities) and the inflow areas of the Xinjiang Production and Construction Corps. Sampling surveys were carried out to obtain the results which would be representative of the whole country and all provinces. At the same time, this survey also selected eight representative cities (states, districts) to conduct a special survey on the key infectious diseases of the migrants.

In this paper, we mainly used the special survey which were about the key infectious diseases of migrants and this survey involved 14000 samples. In order to make the results clearer, we dropped the data which answer was unknown to the vaccination questions. The investigators experienced three stages when selecting the samples: (1) Select townships (towns, streets) according to the probability proportional to size (PPS) sampling method. (2) Select residents in the selected townships (towns, sub-districts). (3) Select individual survey subjects from the selected committees.

\subsection{Measures}

After confirming the samples, on-site investigators (including investigation instructors and investigators) would begin to collect the questionnaire. Before the investigation work officially began, all investigators were required to receive training. All investigators need to participate in investigation training classes and receive special training. This survey was conducted via mobile phones or pads, investigators need to ask questions one by one in the order of the questionnaire and select the corresponding option on the device based on the respondent's answer. After the survey, investigators should be organized to conduct quality check work to ensure the accuracy and scientificity of the answers to the questionnaire.

According to the questionnaire, this survey included demographic information, social economic status, migration and mobility experience, medical and health services, marriage and childbirth, etc. In 2017 MDMS survey, there were factors affecting the prevalence of essential diseases, which included the vaccination information, living environment, living habits and so on.

\subsubsection{Vaccination rates and the awareness of BPHS project}

The outcome of this study was whether the respondent was vaccinated before, and there were nine vaccines asked in detail (HepB, HepA, Fln, DTaP, JE, RaB, MPSV, HF, and TIG vaccine). The answers were yes, no, and unknown. And the vaccination rate was calculated by dividing the number of people who were vaccinated by the total population and multiplying by $100 \%$.

The awareness of BPHSs project was asked by the question "Have you heard of the National Basic Public Health Services Project?". The response was yes or no, which meant 'have heard' or 'not have heard'.

\subsubsection{Demographic characteristics}

In this research, we used six characteristics as independent variables (five were demographic characteristics and one was health characteristic): gender (male/ female); age ( $\leqq 30,31-40,41-50,>50)$; marital status (single, married or having a relationship, divorced or widowed); region (rural or urban); education (middle school or below, high school, three-year technical college, university or above); health status (healthy, almost healthy, unhealthy).

\subsection{Statistical Analysis}

Stata version 14.0 was used as the data analysis software to conduct the statistical analyses. In terms of descriptive statistics, this article used frequency, proportion, and chi-square tests to analyze the characteristics of the sample and the awareness of BPHSs items.

In addition, we also used logistic regressions to analyze the relationship between demographic or health characteristics and awareness of BPHSs project as well as the vaccination rates and awareness of this project, after controlling other variables, including gender, age, marital status, region, education, and health status. Results from logistic regressions were presented as odds ratio (OR) and $95 \%$ confidence intervals $(\mathrm{Cl})$. $\mathrm{P}<0.05, \mathrm{p}<0.01, \mathrm{p}<0.001$ represented different degrees of statistical significance.

To examine the robust of the results, we conducted a sensitivity analysis by fitting different models to examine the robustness of the results. Model 1 was a univariate model which contained no adjustment (Table 2). In model 2, we adjusted for basic demographic characteristics including gender, age, marital status, region, education, and health status (Table 4). We adjusted for all potential confounding factors which included health status, health records,

whether received propaganda from paper, whether received propaganda from promotional video, whether received propaganda from Internet, the time cost from the place of residence to the nearest medical service organization (including community health service center, village infirmary, hospital and so on) (Table 3). 
Table 2

Association between BPHS awareness and vaccination in univariate models (Model 1)

\begin{tabular}{|c|c|c|c|c|c|c|c|c|c|}
\hline \multirow{2}{*}{$\begin{array}{l}\text { BPHS } \\
\text { awareness }\end{array}$} & НерВ & НерА & Fln & DTaP & JE & RaB & MPSV & HF & TIG \\
\hline & OR(95\%Cl) & OR(95\%Cl) & OR(95\%Cl) & OR(95\%Cl) & OR(95\%Cl) & OR(95\%Cl) & OR(95\%Cl) & OR(95\% Cl) & OR(95\%Cl) \\
\hline No & 1 (reference) & 1(reference) & 1(reference) & 1 (reference) & 1 (reference) & 1(reference) & 1 (reference) & 1(reference) & 1 (reference) \\
\hline \multirow[t]{2}{*}{ Yes } & 1.11 & 1.54 & 1.28 & 1.22 & 1.33 & 1.10 & 1.28 & 1.32 & 1.28 \\
\hline & $(1.01-1.22)$ & $(1.38-1.73)$ & $(1.13-1.44)$ & $(1.05-1.43)$ & $(1.14-1.54)$ & $(0.95-1.28)$ & $(1.08-1.51)$ & $(1.03-1.70)$ & $(1.11-1.48)$ \\
\hline $\mathrm{p}$ & $0.0298 *$ & $0.0001^{\star \star \star}$ & $0.0000 * \star *$ & $0.0102 *$ & $0.0001^{\star \star \star}$ & 0.1870 & $0.0033^{\star \star}$ & 0.0267 * & $0.0007 * \star \star$ \\
\hline
\end{tabular}

Table 3

Association between BPHS awareness and vaccination in multivariate models (Model 3)

\begin{tabular}{|c|c|c|c|c|c|c|c|c|c|}
\hline \multirow{2}{*}{$\begin{array}{l}\text { BPHS } \\
\text { awareness }\end{array}$} & НерВ & НерA & FIn & DTaP & JE & $\mathrm{RaB}$ & MPSV & HF & TIG \\
\hline & $\mathrm{OR}(95 \% \mathrm{Cl})$ & OR(95\%Cl) & OR(95\%Cl) & OR(95\% $\mathrm{Cl})$ & $\mathrm{OR}(95 \% \mathrm{Cl})$ & $\mathrm{OR}(95 \% \mathrm{Cl})$ & OR(95\%Cl) & $\mathrm{OR}(95 \% \mathrm{Cl})$ & $\mathrm{OR}(95 \% \mathrm{Cl})$ \\
\hline No & 1 (reference) & 1(reference) & 1 (reference) & 1 (reference) & 1 (reference) & 1(reference) & 1 (reference) & 1 (reference) & 1 (reference) \\
\hline \multirow[t]{2}{*}{ Yes } & 1.34 & 1.69 & 1.27 & 1.32 & 1.89 & 1.49 & 1.27 & 1.07 & 1.17 \\
\hline & $(1.02-1.76)$ & $(1.21-2.37)$ & $(0.89-1.83)$ & $(0.83-2.11)$ & $(1.19-3.00)$ & $(0.93-2.40)$ & $(0.75-2.14)$ & $(0.48-2.38)$ & $(0.79-1.74)$ \\
\hline $\mathrm{p}$ & $0.0000 * \star \star$ & 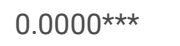 & $0.0000 * * *$ & $0.0000 * * *$ & $0.0000 * \star \star$ & $0.0000 * * *$ & $0.0000 * * *$ & $0.0000 * * *$ & $0.0000 * \star \star$ \\
\hline
\end{tabular}

${ }^{*} \mathrm{p}<0.05, * \star \mathrm{p}<0.01, * \star \star \mathrm{p}<0.001$

Notes: We adjusted for all covariates by adding health records, whether received propaganda from paper, whether received propaganda from promotional video, whether received propaganda from Internet, the time cost from the place of residence to the nearest medical service organization (including community health service center, village infirmary, hospital, etc.). OR: Odds Ratio.

Table 4

Sensitivity analysis on the association between BPHS awareness and vaccination in multivariate models (Model 2)

\begin{tabular}{|c|c|c|c|c|c|c|c|c|c|}
\hline \multirow{2}{*}{$\begin{array}{l}\text { BPHS } \\
\text { awareness }\end{array}$} & НерВ & HepA & FIn & DTaP & JE & $\mathrm{RaB}$ & MPSV & HF & TIG \\
\hline & $\mathrm{OR}(95 \% \mathrm{Cl})$ & $\mathrm{OR}(95 \% \mathrm{Cl})$ & $\mathrm{OR}(95 \% \mathrm{Cl})$ & $\mathrm{OR}(95 \% \mathrm{Cl})$ & OR(95\% Cl) & $\mathrm{OR}(95 \% \mathrm{Cl})$ & $\mathrm{OR}(95 \% \mathrm{Cl})$ & $\mathrm{OR}(95 \% \mathrm{Cl})$ & $\mathrm{OR}(95 \% \mathrm{Cl})$ \\
\hline No & 1 (reference) & 1 (reference) & 1 (reference) & 1 (reference) & 1 (reference) & 1 (reference) & 1 (reference) & 1 (reference) & 1 (reference) \\
\hline \multirow[t]{2}{*}{ Yes } & 1.33 & 1.81 & 1.39 & 1.70 & 1.93 & 1.35 & 1.62 & 1.17 & 1.35 \\
\hline & $(1.08-1.65)$ & $(1.38-2.38)$ & $(1.04-1.86)$ & $(1.15-2.51)$ & $(1.33-2.79)$ & $(0.96-1.90)$ & $(1.06-2.48)$ & $(0.63-2.19)$ & $(0.98-1.86)$ \\
\hline $\mathrm{p}$ & $0.0000 \star \star \star$ & $0.0000 * \star \star$ & $0.0000 * \star \star$ & $0.0000 * \star \star$ & 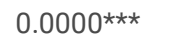 & $0.0001 * \star \star$ & $0.0000 * \star \star$ & $0.0003^{\star \star \star}$ & $0.0001^{\star \star \star}$ \\
\hline \multicolumn{10}{|c|}{${ }^{*} \mathrm{p}<0.05, * \star \mathrm{p}<0.01, * \star \star \mathrm{p}<0.001$} \\
\hline
\end{tabular}

\section{Results}

\subsection{Sample Characteristics}

After removing 3987 samples who did not know their vaccination status, we got a total of 10013 samples. Among these samples, 7658 (76.48\%) samples indicated that they had heard of the BPHSs project, and $2355(23.52 \%)$ indicated that they had not heard of it.

From the perspective of gender, there are 5021 males, accounting for 50.14\%. Among them, 3741(74.51\%) people were aware of it, and $1280(24.90 \%)$ people were not. There were 4992 females, accounting for $49.86 \%$. Among them, those who had known about it were $3917(78.47 \%)$ and $1075(21.53 \%)$ people had not. As to age, there were 4294 people (42.88\%) of the migrants less than or equal to 30 years old, of which 3159 (74.51\%) were aware of the BPHSs project, 1280 (24.90\%) were not. 3155(31.51\%) migrants were 31-40 years old, among them 2516 (79.75\%) people had known this project, 639 (20.25\%) people had not. 1916 (19.14\%) people were 41-50 years old, among them there were 1511 (78.86\%) people had known this and 405 (21.14\%) people did not know. There were 648 people older than 50, of which 472 (72.84\%) people had known this project, and 176(27.16\%) people had not. People who were married or having a relationship took up the largest part in this survey, accounting for $7538(75.28 \%)$, and there were $5916(78.48 \%)$ migrants who had known the project and 1622(21.52\%) people were not aware of this. The number of migrants from rural areas (9891) was much larger than those 
from urban areas (122). Among the migrants with household registration in rural areas, $7582(76.66 \%)$ were aware of this project, which was nearly three times the number of people who had not know this project (2309, accounting for $23.34 \%$ ). Of the migrants with urban household registration, 76 ( $62.3 \%$ ) people had known this projects, which was nearly twice the number of people who had not know it (46, accounting for $37.70 \%)$. In terms of education level, the awareness of BPHSs projects was basically proportional to the level of education. The proportions of the migrants of middle school and below, high school, three-year technical college, university or above who had known this project were $69.59 \%, 75.37 \%, 80.39 \%$, and $79.31 \%$, respectively. In terms of health level, 8563 (85.52\%) were healthy, 1279 (12.77\%) were almost healthy, and 171 (1.71\%) were unhealthy. Among these people, the healthy population has the highest proportion of knowledge about the project, accounting for $77.15 \%$, followed by the almost healthy population, accounting for $73.65 \%$, and the other group accounting for $63.69 \%$ (Table 1 ).

Table 1

Characteristics of the respondents according to awareness of BPHSs project at the baseline

\begin{tabular}{|c|c|c|c|c|c|c|c|}
\hline \multirow[t]{2}{*}{ Characteristics } & \multirow[t]{2}{*}{$N(\%)$} & \multicolumn{4}{|c|}{ Awareness of BPHSs Project } & \multirow[t]{2}{*}{$x^{2}$} & \multirow[t]{2}{*}{$\mathbf{P}$} \\
\hline & & Yes(\%) & $\mathrm{No}(\%)$ & OR & $95 \% \mathrm{Cl}$ & & \\
\hline Total & 10013(100) & 7658(76.48) & $2355(23.52)$ & & & & \\
\hline Gender & & & & & & 21.8061 & 0.000 \\
\hline Male & $5021(50.14)$ & $3741(74.51)$ & $1280(24.90)$ & 1.00 & - & & \\
\hline Female & 4992(49.86) & $3917(78.47)$ & $1075(21.53)$ & 0.89 & $0.72-1.11$ & & \\
\hline Age & & & & & & 49.7791 & 0.000 \\
\hline$<=30$ & 4294(42.88) & $3159(73.57)$ & $1135(26.43)$ & 1.00 & - & & \\
\hline $31-40$ & $3155(31.51)$ & 2516(79.75) & $639(20.25)$ & 1.37 & $1.03-1.81$ & & \\
\hline $41-50$ & 1916(19.14) & 1511(78.86) & $405(21.14)$ & 1.89 & $1.36-2.63$ & & \\
\hline$>50$ & $648(6.47)$ & 472(72.84) & $176(27.16)$ & 1.24 & $0.81-1.90$ & & \\
\hline Marital status & & & & & & 71.1087 & 0.000 \\
\hline Single & $2127(21.24)$ & $1484(69.77)$ & $643(30.23)$ & 1.00 & - & & \\
\hline Married/Having a relationship & 7538(75.28) & $5916(78.48)$ & $1622(21.52)$ & 1.07 & $0.82-1.39$ & & \\
\hline Divorced/widowed & $348(3.48)$ & $258(74.14)$ & $90(25.86)$ & 0.81 & $0.55-1.19$ & & \\
\hline Region & & & & & & 13.8164 & 0.000 \\
\hline Rural & $9891(98.78)$ & 7582(76.66) & $2309(23.34)$ & 1.00 & - & & \\
\hline Urban & $122(1.22)$ & $76(62.30)$ & $46(37.70)$ & 2.00 & $1.19-1.37$ & & \\
\hline Education & & & & & & 93.4010 & 0.000 \\
\hline Middle school or below & 2144(21.41) & 1492(69.59) & $652(30.41)$ & 1.00 & - & & \\
\hline High school & 2712(27.08) & 2044(75.37) & $668(24.63)$ & 1.18 & $0.88-1.59$ & & \\
\hline Three-year technical college & 2948(29.44) & 2370(80.39) & $578(19.61)$ & 1.98 & $1.45-2.71$ & & \\
\hline University or above & $2209(22.06)$ & 1752(79.31) & $457(20.69)$ & 1.69 & $1.20-2.39$ & & \\
\hline Health status & & & & & & 21.8395 & 0.000 \\
\hline Healthy & $8563(85.52)$ & $6606(77.15)$ & 1957(22.85) & 1.00 & - & & \\
\hline Almost healthy & 1279(12.77) & $942(73.65)$ & $337(26.35)$ & 1.01 & $0.74-1.39$ & & \\
\hline Unhealty & 171(1.71) & $110(21.65)$ & $398(78.35)$ & 0.35 & $0.17-0.73$ & & \\
\hline
\end{tabular}

\subsection{Association between characteristics and the awareness of BPHSs project}

In this research, male, $\leqq 30$ years old, single, rural, middle school or below, healthy population were set as the reference group. From the chi-square test results (Table 1), we found that all the characteristics we analyzed were significantly associated (all p values $<0.001$ ) with migrants' awareness of BPHSs project. The connection between gender and the awareness was significant (OR: $0.89,95 \% \mathrm{Cl}: 0.72-1.11)$. The number of people who were aware of the BPHSs project was higher among those who were married or having a relationship (OR: 1.07, 95\% $\mathrm{Cl}: 0.82-1.39)$, from urban areas (OR: $2.00,95 \% \mathrm{Cl}$ : 0.82-1.39), almost healthy (OR: 1.01, 95\%Cl: 0.74-1.39) (Table 1). 
We tested the frequency and proportions of the awareness rates of BPHSs project among migrants who had been already vaccinated with one of the nine recommended vaccines at least. And at the same time, we analyzed the vaccination rates among the migrants who were aware or unaware of the BPHSs project (Fig. 1). The number of individuals who had known the BPHSs project among the vaccinated people were almost 3 to 4 times than those had not. Among the HepA, HF, JE, MPSV, TIG vaccine there were more than $80 \%$ people who were conscious of this project, accounting for $81.97 \%$, $80.93 \%$, $80.68 \%$, $80.28 \%, 80.14 \%$, respectively. Others were nearly to $80 \%$, and people taking FIn vaccine and had learned the project took up for $79.83 \%$, while the DTaP vaccine was $79.60 \%$, the $\mathrm{RaB}$ vaccine was $78.03 \%$ and the HepB vaccine was $77.25 \%$ (Table 2 ).

\subsection{The association between awareness rates of BPHSs project and vaccination rates}

In order to figure out the association between the awareness rates of BPHSs project and vaccination rates, we conducted logistic regressions. The group who had not known the BPHSs project was set as the reference group. The results showed that in HepA vaccine(OR: 1.54, 95\%Cl: 1.38-1.73), Fln vaccine (OR: $1.28,95 \% \mathrm{Cl}: 1.13-1.44)$, JE vaccine (OR: 1.33, 95\% Cl: 1.14-1.54), TIG vaccine (OR:1.28, 95\% Cl: 1.11-1.48) there were significant association between the vaccination and awareness of BPHSs project (all p values < 0.001). The significance in HepB (OR: 1.11, 95\%Cl: 1.01-1.22), DTaP (OR: 1.22, 95\% Cl: 1.05-1.43), MPSV (OR: 1.28, 95\% Cl: 1.08-1.51), HF (OR: 1.32, 95\% Cl: 1.03-1.70) was slighter ( $<<0.05)($ Table 3 ). According to the sensitivity analysis, the results were robust in different models. In the multivariate models, there were also significant association between them.

\section{Discussion}

To our knowledge, this is the first nationwide cross-sectional study which examined the association of between awareness of basic public health services and vaccination rates among migrants aged 15 years or above in China. In this study, we found that there was a significant relationship between the BPHSs project and vaccination. In addition, the demographic and health characteristics were highly associated with BPHSs project.

The General Office of the Central Committee of the Communist Party of China and the General Office of the State Council had introduced the "Suggestions on Further Strengthening the Services and Management of the Migrants" in 2007, pointing out that the number of the migrants continued to grow, and the services and management of the migrants should be strengthened. The government need to pay great attention to medical and health and family planning services for the migrants, and provide free services equivalent to those of the local registered population in terms of disease prevention, infectious disease prevention, vaccination, and maternal and child health care. The document emphasized that the migrants could enjoy the same preferential policies as other citizens.

From the perspective of the association between the migrants and health characteristics of the BPHSs project, the migrants' awareness rates of the BPHSs project were significantly related to gender, age, marital status, region, education level and health status. As to gender, in the division of labor in traditional Chinese families, women were more responsible for children's vaccination, so women would have a better understanding of vaccination and basic public health services in the process.

In regard to age, there was a strong and significant relationship between age and the awareness of BPHSs project. The two groups, 31-40 and $41-50$, knew the project best, and the number of people who had known about it was close to $80 \%$. One possible explanation was these two groups were in the middle and young age group and had more channels for obtaining information than the elderly group. At the same time, they had a higher level of awareness of social affairs than the young group. This group might also understand the project better because of children, so they may pay more attention to child health care, vaccination and other needs. From the perspective of marital status, the vaccination rate of married, cohabiting, or having relationship was higher than that of unmarried, divorced, or widowed groups, which might also be related to the needs of children.

In terms of regions, the proportion of migrants in urban areas who had known about the project was lower than in rural areas. This might because that migrants in urban areas had less contact with the community health service centers responsible for providing basic public health services. In regard to education level, as a whole, the higher the level of education, the higher the awareness rate of BPHSs project. This was related to the higher level of education that paid more attention to their own health status and related health services. As to health level, the higher the health level, the higher the awareness rate of the BPHSs project. This article conjectured that this reflected the mutual promotion relationship between the two aspects.

Different from previous research results [21], the awareness rate of BPHSs project of migrants in the present study was 76.48\%, which was much higher than the results of previous studies. The correlation between the awareness rate of BPHSs project and vaccination could be explained from two aspects: On the one hand, because vaccination was a very important item in the BPHSs program, the BPHSs project helped this population to further understand vaccination, thereby promoting the increase of vaccination rates. On the other hand, vaccination could also reversely promote the residents' understanding of the BPHSs project. By receiving vaccination at the vaccination sites, the migrants had more opportunities to receive the publicity of basic public health services, and then learn more about this project. The high correlation between this project and vaccination might mean that strengthening the awareness of BPHSs project could improve vaccination rates to a certain extent, thereby promoting the development of national epidemic prevention work and improving the health literacy and status of residents.

Based on the relevance of the BPHSs project and vaccination, we suggest that the government should further enhance the publicity of this project and continuously expand the scope of the project through the Internet, television and other means. Besides, strengthening the project where vaccination services were carried out was also extremely important.

In order to strengthen the research on the awareness rates of the BPHSs project and the vaccination work of the migrants, we planned to study the causal relationship between the project and vaccination in the future, using the latest data in the research process. At the same time, we would like to study the

Page 6/9 
vaccination status of migrants' children and their awareness of BPHSs.

Our research certainly had some limitations. First, the populations in the existing data were all born in 2006 or before. The BPHSs project started in 2009 , and it was not possible to better test the impact of this project on the vaccination situation of the migrants born before and after the implementation of the project. Second, this study could only explain the relationship between the awareness of BPHSs project and vaccination, but cannot explain the causal relationship between them. Vaccination may also cause the migrants to know basic public health services in the reverse direction. This issue needed further research. Third, the data in this article were second-hand data. Many factors (such as health literacy, parental education, etc.) were not available, which might affect the results of the research.

\section{Conclusion}

In this study, we found that there was a strong relationship between the awareness rate of BPHSs project and vaccination in the migrants, and the awareness rate of BPHSs had a strong correlation with the demographic and health characteristics of the migrants. Our findings suggest that the promotion of basic public health services had a beneficial effect on the national recommended vaccination coverage, especially for the migrants with relatively low vaccine coverage. Future research should explore the mechanism of promoting BPHSs project on the vaccination coverage rates, and explore service models based on basic public health service packages to further increase the vaccination coverage rates of the migrants.

\section{Abbreviations}

BPHSs project: National Basic Public Health Services project

\section{Declarations}

\section{Authors' Contributions}

Conceptualization, J.W. J.Z., Y.B., and J.L.; methodology, J.W. and J.L.; software, Y.B.; validation, J.W. J.Z., Y.B., X.W., Y.C. and J.L.; formal analysis, Y.B.; data curation, Y.B. and J.L.; writing-original draft preparation, J.W., J.Z. Y.B. and J.L.; writing-review and editing, J.W. J.Z., Y.B., X.W., Y.C., and J.L.; visualization, Y.B.; supervision, Y.B. J.L.; funding acquisition, J.W. and J.L. All authors have read and agreed to the final version of the manuscript.

\section{Funding}

This work was funded by the Joint Funds of the National Natural Science Foundation of China (Grant Number 72042002, 71934002, 72122001); the Funds for International Cooperation and Exchange of the National Natural Science Foundation of China (Grant Number 72061160491); the National Science and Technology Key Projects on Prevention and Treatment of Major infectious disease of China (grant number 2020ZX10001002); the National Key Research and Development Project of China (grant numbers 2020YFC0846300, 2019YFC1710301).

\section{Availability of data and materials}

Data are available from the corresponding author by request.

There was no administrative permission required to access the data of 2017 Migrant Population Dynamic Monitoring Survey (MDMS) from National Health and Family Planning Commission of the People's Republic of China(NHFPC).

\section{Ethics approval and consent to participate}

This study was presented to the Medical Health and Human Resources Ethics Committee of Renmin University of China. The Committee confirmed that its approval was not required according to the guidelines of the committee refering to "Measures for the Ethical Review of Biomedical Research Involving People" introduced by National Health Commission of the People's Republic of China (http://www.gov.cn/gongbao/content/2017/content_5227817.htm). And we also conducted the research in accordance with the Declaration of Helsinki.

The 2017 Migrants Population Dynamic Monitoring Survey was approved by the National Health and Family Planning Commission Ethics Review Board, and all participants provided informed consent. All participants received a written informed consent form and an oral explanation of the purpose and content of the research. When minors (<18years old) are involved in research, consent was obtained from their parents or guardians.

\section{Consent for publication}

Not applicable.

\section{Competing interests}

The researchers declare no conflict of interest.

\section{References}


1. The State Council of the People's Republic of China: The guidelines of development of community health services in urban areas. http://www.nhc.gov.cn/bgt/pw10604/200606/4e4cda565b4a452db1bb7a39aa192234.shtml(2006)Accessed 2 Jun 2006.

2.The State Council of the People's Republic of China: The suggestions of deepening reform of public health and medicine undertaking. The State Council of the People's Republic of China. http://www.gov.cn/gongbao/content/2009/content_1284372.htm (2006). Accessed 17 Mar 2009.

3. Ministry of Health, Ministry of Finance, National Population and Family Planning Commission of the People's Republic of China: Suggestions on promoting the gradual equalization of basic public health services. http://www.gov.cn/zwgk/2009-07/14/content_1365335.htm (2009) Accessed 14 Jul 2009.

4. Larson H.J., Jarrett C., Eckersberger E., Smith D.M.D., Paterson P. Understanding vaccine hesitancy around vaccines and vaccination from a global perspective: A systematic review of published literature, 2007-2012. Vaccine. 2014; doi: 10.1016/j.vaccine.2014.01.081

5. Nan W, Ling T, Wuqi Q. Review of vaccine-related policies in the 60 years since the founding of the People's Republic of China. Journal of Medical Research. 2010; doi: 10.3969/j.issn.1673-548X.2010.08.006

6. Jiangmei Q. Progress in basic public health service projects in China. Chinese Journal of Public Health. 2017; doi:10.11847/zgggws2017-33-09-01

7.Jing G, Fei S, Hui F, Liping X, Yaqin W. Analysis on the access to the basic public health care services and influencing factors among migrants. Chinese Journal of Health Policy. 2016; doi: 0.3969/j.issn.1674-2982.2016.08.013

8. Qingqing G, Jinxia Y, Chunlin Y, Caihong X, Wei Y. Study on basic public health ability of primary health care workers. Health Economics Research. 2016; doi: 10.14055/j.cnki.33-1056/f.20160704.011

9. Fang W, Yongbin L, Xue D, Tao D. The national essential public health services project in China: progress and equity. Chinese Journal of Health Policy. 2013; doi:10.3969/j.issn.1674-2982.2013.05.002

10. Kuimeng S, Ling X, Xiaojie S, Hui L, Haipeng W, Yan D, Ying X, Qingyue M. Analysis on the status of the basic public health service functions of urban and rural primary medical and health institution. Chinese Journal of Health Informatcs and Management. 2012; doi:10.3969/j.issn.1672-

5166.2012.01.005

11. Li C, Lan Y, Zhan S. The current status, problems and countermeasures of the equalization of basic public health services in China. Chinese Journal of Public Health. 2012; doi:10.11847/zgggws-2012-28-02-35

12. Bao L, Shanlian H, Haixia X, Jianhui G. Indices of the equality of essential public health services in China. Chinese Journal of Health Policy. 2009; doi:10.3969/j.issn.1674-2982.2009.06.003

13. Xianchao G, Ling H. The Situation and Influence Factors of Health Records of Floating Population--Based on the National Dynamic Monitoring Data of Floating Population Survey of Sichuan Province in 2014.Population and Development. 2016; doi:10.3969/j.issn.1674-1668.2016.03.014

14. Ji Z, Chushi N, Xiongyan T, Baosong L. Analysis of the status of community management of chronic diseases in basic public health services. Chinese Journal of Prevention and Control of Chronic Diseases. 2017; doi: 10.16386/j.cjpccd.issn.1004-6194.2017.04.021

15. Xiuqin W, Tengteng H, Jie Z, Qingqi Z, Yunting Z, Chun C. Relationship between the health literacy and utilization of basic public health services among diabetics. China Journal of Health Education. 2015; doi: 10.16168/j.cnki.issn.1002-9982.2015.05.006

16. Xiuqin W, Tengteng H, Jie Z. Correlation between the health literacy and utilization of basic public health services among huperpietics in communities. Chinese General Practice. 2015; doi: 10.3969/j.issn.1007-9572.2015.13.010

17. Enchun P, Qin Q, Yuan L, Hao Y, Sihong C, Yi W, Jing W. Cross-sectional survey on the health management of hypertension and diabetes mellitus patients conducted by medical staff in primary health care service centers. Chinese General Practice. 2014; doi: 10.3969/j.issn.1007-9572.2014.28.010

18. Aihua H, Cuicui L, Bo P. Guangdong Residents' Awareness and Satisfaction with China's National Essential Public Health Services. Chinese General Practice. 2019; doi:10.12114/j.issn.1007-9572.2019.04.008

19. Leixia W, Yijun C, Jie L, Zhijie C, Chunsheng Y. Investigation on awareness rate and satisfaction of key population in basic public health service in Gansu. Chinese Journal of Public Health Management. 2018; doi: 10.19568/j.cnki.23-1318.2018.06.013

20. Li D, Yao G, Ying C, Wenlong C, Xiaoqing Z. Analysis on awareness rate and satisfaction of resident's basic public health service in 6 prefectures ( cities) of Yunnan Province. Soft Science of Health. 2018; doi:10.3969/j.issn.1003-2800.2018.08.011

21. Jing G, Hongling Y, Linglin L, Fei S. Status quo and determinants of awareness on basic public health service among migrant population. Chinese Journal of Public Health. 2019; doi:10.11847/zgggws1117247 
22. Shiyu X, Xinlong G, Shuo S, Guimei C, Ren C. Comparative research on awareness rate of basic public health services and satisfactory degree among urban and rural residents on goal of equalization. Anhui Medical Journal. 2017; doi: 0.3969/j.issn.1000-0399.2017.09.039

\section{Figures}

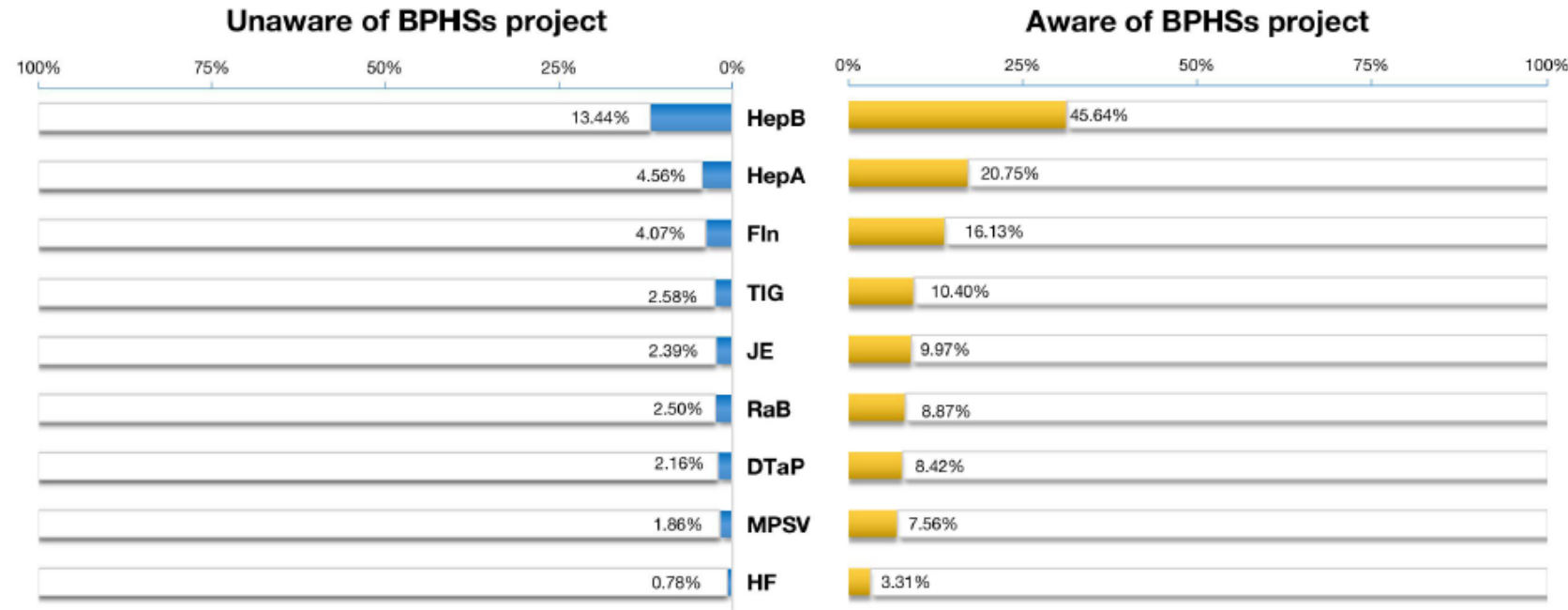

\section{Figure 1}

Vaccination rates among migrants who were aware or unaware of the BPHSs project 